\title{
EFFECT OF PREOPERATIVE INTRAVENOUS DEXAMETHASONE ON POSTOPERATIVE SORE THROAT FOLLOWING ENDOTRACHEAL INTUBATION
}

\author{
Letha Janardhan ${ }^{1}$, Nidhi Rani Gupta ${ }^{2}$
}

${ }^{1}$ Associate Professor, Department of Anaesthesia, Government T. D. Medical College and Hospital, Alappuzha, Kerala. ${ }^{2}$ Lecturer, Department of Anaesthesia, Government T. D. Medical College and Hospital, Alappuzha, Kerala.

\section{ABSTRACT}

\section{BACKGROUND}

Postoperative sore throat (POST) is a common complaint following endotracheal intubation for general anaesthesia. The aim is to study the effectiveness of intravenous dexamethasone in postoperative sore throat and the side effects associated with its use.

\section{MATERIALS AND METHODS}

The study was conducted in patients undergoing general anaesthesia with endotracheal intubation in our department in Government T. D. Medical College, Alappuzha. Altogether 80 patients were studied who were divided into a control group and a study group by convenient allocation so that each group comprises 40 patients. Control group received $2 \mathrm{~mL}$ of normal saline intravenously and study group received $8 \mathrm{mg}$ of dexamethasone intravenously before induction of anaesthesia. Patients were asked about the presence of sore throat at different time intervals for the next 24 hours after surgery. Also, presence of gastric irritation and RBS values were checked every $6^{\text {th }}$ hour for 24 hours.

\section{RESULTS}

In the first 6 hours after surgery, majority of patients in the control group had sore throat in the initial 30 minutes whereas in the dexamethasone group, less number of patients complained of sore throat. But thereafter complaints of sore throat decreased in both the groups. Most of the patients who had sore throat in either group belonged to the 'mild' category. Nobody in either group had severe sore throat. When questioned 30 minutes after surgery, 23 patients in the control group and only 12 patients in the dexamethasone group had sore throat which is a significant difference as stated by the p value. From 7 to 24 hours, majority of patients in either group did not experience sore throat. Mild sore throat was present in few patients in both the groups. No patient in either group had moderate or severe sore throat. Majority of patients enrolled in the study in both the groups did not complain of any postoperative gastric irritation.

\section{CONCLUSION}

Prophylactic dexamethasone decreases the incidence of postoperative sore throat especially in the $1^{\text {st }}$ hour after surgery. Also gastric irritation was not found to be a significant side effect but postoperative.

\section{KEYWORDS}

Postoperative Sore Throat, Gastric Irritation, Dexamethasone.

IOW TO CITE THIS ARTICLE: Janardhan L, Gupta NR. Effect of preoperative intravenous dexamethasone on postoperative sor rroat following endotracheal intubation. J. Evolution Med. Dent. Sci. 2017;6(78):5531-5535, DOI: 10.14260/jemds/2017/1202

\section{BACKGROUND}

Postoperative sore throat (POST) is a common complication of general anaesthesia with endotracheal intubation. The reported incidence of postoperative sore throat varies from 21 to $65 \%$. POST following tracheal intubation is due to trauma to the airway mucosa. Various pharmacological and non-pharmacological trials have been tried for attenuating POST with variable success.1,2 Tracheal intubation is associated with an increase of polymorphonuclear cells in the tracheal tissue and plasma levels of Interleukin-6, suggesting an inflammatory response to the presence of the endotracheal tube itself or to some aspect of the intubation process. $3,4,5$

'Financial or Other Competing Interest': None.

Submission 09-08-2017, Peer Review 17-09-2017,

Acceptance 23-09-2017, Published 28-09-2017.

Corresponding Author:

Nidhi Rani Gupta

Lecturer, Department of Anaesthesia,

J Block, TDMCH Vandanam-688005,

Alappuzha, Kerala.

E-mail: drnidhigarg@gmail.com

DOI: $10.14260 /$ jemds/2017/1202
Dexamethasone, a glucocorticosteroid, has been shown to decrease postoperative sore throat in patients requiring endotracheal intubation for general anaesthesia due to its anti-inflammatory effects like decreased release of vasoactive factors, diminished secretion of lipolytic and proteolytic enzymes, decreased extravasation of leukocytes to areas of injury and reduced expression of proinflammatory enzymes, such as COX-2 and Nitric Oxide Synthase. Moreover, prophylactic dexamethasone has been shown to be effective in reducing the incidence of laryngeal oedema and postoperative nausea \& vomiting.6,7,8 Corticosteroids may have other beneficial effects on patient recovery. ${ }^{9,10}$ They can generate a subjective sense of well-being, independent of their disease status, which can lead to a faster discharge from the hospital.11,12,13 Possible side effects of corticosteroids such as significant hyperglycaemia, retardation of wound healing, susceptibility to infection and gastrointestinal haemorrhage have not been noted with short-term use $(<24$ hours). ${ }^{14}$ This study was undertaken to determine the efficacy of prophylactic intravenous dexamethasone to reduce the incidence of postoperative sore throat. 


\section{MATERIALS AND METHODS}

\section{Study Setting}

This study was conducted under the Department of Anaesthesiology, Govt. T. D. Medical College Hospital, Alappuzha after getting approval from Institutional Research Committee and Ethical Committee.

\section{Study Period}

March 2013 to February 2014

\section{Study Design}

- A non-randomised control study.

- The patients were conveniently allocated into 2 groups named ' $C$ ' and ' $D$ '.

- Group C -received $2 \mathrm{~mL}$ of intravenous injection of normal saline.

- Group D-received $8 \mathrm{mg}(2 \mathrm{~mL})$ of intravenous dexamethasone injection.

\section{Inclusion Criteria}

- Elective surgeries done under general anaesthesia with endotracheal intubation

- $\quad$ Age between 30 and 50 years

- Weight between 50 and $70 \mathrm{~kg}$.

- Height between 145 to $170 \mathrm{~cm}$.

- ASA grade I.

- Duration of General Anaesthesia more than 1 hour.

- $\quad$ Either sex

\section{Exclusion Criteria}

- Patient not willing to take part in this study.

- Patients with a history of recent sore throat or upper respiratory tract infection.

- Pregnancy, breastfeeding.

- Current use of corticosteroids.

- Immunocompromised patients.

- Mallampati grade $>2$.

- Patients with history of recent anti-inflammatory medicine intake.

- Patients with hypertension, cardiac disease, diabetes mellitus, acid peptic disease, glaucoma, psychiatric medications.

- Those who require more than one intubation attempt.

- Procedures in which throat packs are used.

- Oropharyngeal surgeries.

\section{Sample Size}

$\mathrm{n}=(\mathrm{Z} \alpha+\mathrm{Z} 1-\beta) 2 \times[\mathrm{P} 1 \mathrm{Q} 1+\mathrm{P} 2 \mathrm{Q} 2 /(\mathrm{P} 1-\mathrm{P} 2) 2]$, where $\mathrm{Z} \alpha=1.96$, $\mathrm{Z} 1-\beta=0.8$,

$\mathrm{P} 1=$ proportion of POST in intervention arm (20\%).

P2 = proportion of POST in control arm (56.3\%).

P1 \& P2 were defined in accordance to study done by Suhara Beevi et al. ${ }^{15}$

$\mathrm{Q} 1=100-\mathrm{P} 1, \mathrm{Q} 2=100-\mathrm{P} 2$

$\mathrm{n}=24$.

So we took 40 subjects in each study group.

\section{Methodology}

- Detailed pre-anaesthetic check-up and airway assessment was done.

- $\quad$ Age, weight and height were noted.

- Vital signs recorded.
- $\quad$ FBS value on the morning of surgery was recorded.

- Written informed consent was obtained from the patient.

\section{Premedication}

- Tab. Omeprazole $20 \mathrm{mg}$ - on the preoperative night and at 6:00 am on the day of surgery.

- Tab. Ondansetron $4 \mathrm{mg}$ - on the preoperative night and at 6:00 am on the day of surgery.

- Tab. Alprazolam $0.25 \mathrm{mg}$ - on the preoperative night and at 6:00 am on the day of surgery.

\section{Technique}

The guide prepared the intravenous injection solution for both the groups in $2 \mathrm{~mL}$ syringes.

The anaesthesia nurse administered the injection to the patients in each group, as per the allocation and under the directions of the guide. The allocated intravenous injection was administered to the patient 60 minutes prior to induction.

The investigator observed the patients in each group.

Standard non-invasive monitoring was done which included continuous electrocardiography, non-invasive blood pressure, pulse rate and peripheral oxygen saturation using pulse oximetry and EtCO2 using capnograph.

Following 3 minutes of preoxygenation, induction of anaesthesia was done with glycopyrrolate $0.2 \mathrm{mg}$ IV, midazolam $0.02 \mathrm{mg} / \mathrm{kg} \mathrm{IV}$, pethidine $0.5 \mathrm{mg} / \mathrm{kg} \mathrm{IV}$, lignocaine $1.5 \mathrm{mg} / \mathrm{kg} \mathrm{IV}$, propofol $2 \mathrm{mg} / \mathrm{kg}$ IV followed by succinylcholine $2 \mathrm{mg} / \mathrm{kg}$ IV to facilitate orotracheal intubation with sterile polyvinylchloride endotracheal tube with an internal diameter of $7.0 \mathrm{~mm}$ for women and $8.5 \mathrm{~mm}$ for men. The endotracheal tubes were lubricated with sterile water at room temperature.

Immediately after intubation, cuff was inflated with room air required to prevent an audible air leak with a cuff pressure less than $25 \mathrm{~cm}$ of $\mathrm{H}_{2} \mathrm{O}$ measured by using cuff pressure monitor. Anaesthesia was maintained with 33\% oxygen in nitrous oxide along with an inhalational anaesthetic agent. Residual neuromuscular block was antagonised with neostigmine $0.05 \mathrm{mg} / \mathrm{kg} \quad \mathrm{IV}$ and glycopyrrolate $0.4 \mathrm{mg}$ IV on completion of surgery. Extubation was done after oropharyngeal suction under direct vision.

\section{Assessment}

The patients were assessed by the investigator, every 15 minutes in the $1^{\text {st }}$ postoperative hour, then every 30 minutes till 4 hours, then hourly till 12 hours and then 2 hourly till 24 hours postoperative.

GRBS and gastric irritation if any was also noted and recorded $6^{\text {th }}$ hourly.

\section{Grading}

Postoperative sore throat was graded using a four-point scale (0-3)-

0 - no sore throat.

1 - Mild sore throat (Complained of sore throat only on asking).

2 - Moderate sore throat (Complained of sore throat on his/ her own).

3 - Severe sore throat (Change of voice or hoarseness, associated with throat pain). 


\section{Statistical Analysis}

Baseline data was entered in Microsoft Excel sheet. Qualitative variables were summarised using proportions with 95\% CI. Quantitative variables were summarised using mean with standard deviation. Test of significance such as $t$ test for Qualitative variables \& chi square test for Quantitative variables were done.

\section{RESULTS}

Eighty patients of either sex between 30 and 50 years of age posted for surgery under general anaesthesia with endotracheal intubation were divided into 2 equal groups of 40 each. Group C patients received $2 \mathrm{~mL}$ of intravenous injection of normal saline. Group D patients received $8 \mathrm{mg}$ (2 $\mathrm{mL}$ ) of intravenous dexamethasone injection. Postoperative assessment of sore throat was done every 15 minutes up to 1 hour, every 30 minutes between 1 to 4 hours, then hourly between 4 to 12 hours and then every 2 hourly between 12 to 24 hours. Random blood sugar and any complaints of gastric irritation were recorded every $6^{\text {th }}$ hourly for 24 hours postoperatively. Majority of the patients belonged to the ages between 40 - 50 years in both the control group (55\%) and dexamethasone group (67.5\%). Mean age in control group was 39.9 years with standard deviation of 6.7. In the dexamethasone group, the mean was 41.6 years with a standard deviation of 5.7. Statistical analysis using independent $t$ - test revealed a p value of $>0.05$. Analysis of the gender distribution across the 2 groups (table 2, fig 2) showed that in both groups females formed the majority i.e. in control group $72.5 \%$ and in dexamethasone group $52.5 \%$. Chi square analysis of this data yielded a p value of $>0.05$. Mean height in control group was $158.5 \mathrm{~cm}$ with SD of 5.0. In the dexamethasone group, the mean was $160 \mathrm{~cm}$ with a SD of 6.2. Statistical analysis using independent $t$ - test revealed a $\mathrm{p}$ value of $>0.05$. Mean weight in control group was $57.6 \mathrm{~kg}$ with SD of 4.6. In the dexamethasone group, the mean was $59.7 \mathrm{~kg}$ with a SD of 5.6. Statistical analysis using independent $\mathrm{t}$ - test revealed a $\mathrm{p}$ value of $>0.05$. Mean duration of general anaesthesia in control group was 2.3 hours with a SD of 0.6 and in the dexamethasone group the mean was 2.2 hours with a SD of 0.6. Statistical analysis using independent t-test revealed a $\mathrm{p}$ value of $>0.05$. Mean FBS in the control group was $81.4 \mathrm{mg} \%$ with a standard deviation of 12.4 and in the dexamethasone group was $82.5 \mathrm{mg} \%$ with a standard deviation of 11.7. Statistical analysis using independent t-test revealed a $\mathrm{p}$ value $>0.05$.

\begin{tabular}{|c|c|c|c|c|c|c|}
\hline Time & Group & Nil & Mild & Moderate & Z\# & $\mathbf{p}$ \\
\hline \multirow{2}{*}{15 min. } & Control & $13(32.5)$ & $24(60)$ & $3(7.5)$ & \multirow{2}{*}{1.91} & \multirow{2}{*}{0.056} \\
\hline & Dexamethasone & $21(52.5)$ & $18(45)$ & $1(2.5)$ & & \\
\hline \multirow{2}{*}{$30 \mathrm{~min}}$. & Control & $17(42.5)$ & $21(52.5)$ & $2(5)$ & \multirow{2}{*}{$2.3^{*}$} & \multirow{2}{*}{0.021} \\
\hline & Dexamethasone & $28(70)$ & $10(25)$ & $2(5)$ & & \\
\hline \multirow{2}{*}{$45 \mathrm{~min}}$. & Control & $26(65)$ & $13(32.5)$ & $1(2.5)$ & \multirow{2}{*}{1.81} & \multirow{2}{*}{0.071} \\
\hline & Dexamethasone & $33(82.5)$ & $7(17.5)$ & $0(0)$ & & \\
\hline \multirow{2}{*}{$1 \mathrm{hr}}$. & Control & $27(67.5)$ & $11(27.5)$ & $2(5)$ & \multirow{2}{*}{1.62} & \multirow{2}{*}{0.105} \\
\hline & Dexamethasone & $33(82.5)$ & $7(17.5)$ & $0(0)$ & & \\
\hline \multirow{2}{*}{$1.5 \mathrm{hrs}}$. & Control & $32(80)$ & $7(17.5)$ & $1(2.5)$ & \multirow{2}{*}{0.94} & \multirow{2}{*}{0.347} \\
\hline & Dexamethasone & $35(87.5)$ & $5(12.5)$ & $0(0)$ & & \\
\hline \multirow{2}{*}{2 hrs. } & Control & $32(80)$ & $7(17.5)$ & $1(2.5)$ & \multirow{2}{*}{1.64} & \multirow{2}{*}{0.102} \\
\hline & Dexamethasone & 37 (92.5) & $3(7.5)$ & $0(0)$ & & \\
\hline \multirow{2}{*}{$2.5 \mathrm{hrs}}$. & Control & $33(82.5)$ & $7(17.5)$ & $0(0)$ & \multirow{2}{*}{1.34} & \multirow{2}{*}{0.179} \\
\hline & Dexamethasone & $37(92.5)$ & $3(7.5)$ & $0(0)$ & & \\
\hline \multirow{2}{*}{$3 \mathrm{hrs}}$. & Control & $33(82.5)$ & 7 (17.5) & $0(0)$ & \multirow{2}{*}{1.34} & \multirow{2}{*}{0.179} \\
\hline & Dexamethasone & $37(92.5)$ & $3(7.5)$ & $0(0)$ & & \\
\hline \multirow{2}{*}{$3.5 \mathrm{hrs}}$. & Control & $34(85)$ & $6(15)$ & $0(0)$ & \multirow{2}{*}{1.05} & \multirow{2}{*}{0.292} \\
\hline & Dexamethasone & $37(92.5)$ & $3(7.5)$ & $0(0)$ & & \\
\hline \multirow{2}{*}{4 hrs. } & Control & $34(85)$ & $6(15)$ & $0(0)$ & \multirow{2}{*}{1.05} & \multirow{2}{*}{0.292} \\
\hline & Dexamethasone & $37(92.5)$ & $3(7.5)$ & $0(0)$ & & \\
\hline \multirow{2}{*}{$5 \mathrm{hrs}}$. & Control & $34(85)$ & $6(15)$ & $0(0)$ & \multirow{2}{*}{1.05} & \multirow{2}{*}{0.292} \\
\hline & Dexamethasone & $37(92.5)$ & $3(7.5)$ & $0(0)$ & & \\
\hline $6 \mathrm{hrc}$ & Control & $34(85)$ & $6(15)$ & $0(0)$ & 105 & 0292 \\
\hline o nrs. & Dexamethasone & $37(92.5)$ & $3(7.5)$ & $0(0)$ & 1.05 & 0.292 \\
\hline
\end{tabular}




\begin{tabular}{|c|c|c|c|c|c|c|}
\hline Time & Group & Nil & Mild & Moderate & Z\# & $\mathbf{P}$ \\
\hline \multirow{2}{*}{$7 \mathrm{hrs.}$} & Control & $34(85)$ & $6(15)$ & $0(0)$ & \multirow{2}{*}{1.48} & \multirow{2}{*}{0.139} \\
\hline & Dexamethasone & 38 (95) & $2(5)$ & $0(0)$ & & \\
\hline \multirow{2}{*}{$8 \mathrm{hrs}}$. & Control & $35(87.5)$ & $5(12.5)$ & $0(0)$ & \multirow{2}{*}{1.18} & \multirow{2}{*}{0.238} \\
\hline & Dexamethasone & $38(95)$ & $2(5)$ & $0(0)$ & & \\
\hline \multirow{2}{*}{9 hrs. } & Control & $36(90)$ & $4(10)$ & $0(0)$ & \multirow{2}{*}{0.84} & \multirow{2}{*}{0.399} \\
\hline & Dexamethasone & $38(95)$ & $2(5)$ & $0(0)$ & & \\
\hline \multirow{2}{*}{$10 \mathrm{hrs}$. } & Control & $37(92.5)$ & $3(7.5)$ & $0(0)$ & \multirow{2}{*}{0.46} & \multirow{2}{*}{0.646} \\
\hline & Dexamethasone & $38(95)$ & $2(5)$ & $0(0)$ & & \\
\hline \multirow{2}{*}{$11 \mathrm{hrs}$. } & Control & $37(92.5)$ & $3(7.5)$ & $0(0)$ & \multirow{2}{*}{0.46} & \multirow{2}{*}{0.646} \\
\hline & Dexamethasone & $38(95)$ & $2(5)$ & $0(0)$ & & \\
\hline \multirow{2}{*}{$12 \mathrm{hrs}$. } & Control & $37(92.5)$ & $3(7.5)$ & $0(0)$ & \multirow{2}{*}{0.46} & \multirow{2}{*}{0.646} \\
\hline & Dexamethasone & 38 (95) & $2(5)$ & $0(0)$ & & \\
\hline \multirow{2}{*}{$14 \mathrm{hrs}$. } & Control & $37(92.5)$ & $3(7.5)$ & $0(0)$ & \multirow{2}{*}{0.46} & \multirow{2}{*}{0.646} \\
\hline & Dexamethasone & $38(95)$ & $2(5)$ & $0(0)$ & & \\
\hline \multirow{2}{*}{$16 \mathrm{hrs}$. } & Control & $37(92.5)$ & $3(7.5)$ & $0(0)$ & \multirow{2}{*}{0.46} & \multirow{2}{*}{0.646} \\
\hline & Dexamethasone & $38(95)$ & $2(5)$ & $0(0)$ & & \\
\hline \multirow{2}{*}{$18 \mathrm{hrs}$. } & Control & $37(92.5)$ & $3(7.5)$ & $0(0)$ & \multirow{2}{*}{0.46} & \multirow{2}{*}{0.646} \\
\hline & Dexamethasone & 38 (95) & $2(5)$ & $0(0)$ & & \\
\hline \multirow{2}{*}{$20 \mathrm{hrs}$. } & Control & $37(92.5)$ & $3(7.5)$ & $0(0)$ & \multirow{2}{*}{0.46} & \multirow{2}{*}{0.646} \\
\hline & Dexamethasone & $38(95)$ & $2(5)$ & $0(0)$ & & \\
\hline \multirow{2}{*}{$22 \mathrm{hrs}$. } & Control & $37(92.5)$ & $3(7.5)$ & $0(0)$ & \multirow{2}{*}{0.46} & \multirow{2}{*}{0.646} \\
\hline & Dexamethasone & $38(95)$ & $2(5)$ & $0(0)$ & & \\
\hline $24 \mathrm{hrc}$ & Control & 37 (92.5) & $3(7.5)$ & $0(0)$ & & 0646 \\
\hline $24 \mathrm{hrs}$. & Dexamethasone & $38(95)$ & $2(5)$ & $0(0)$ & 0.46 & 0.646 \\
\hline
\end{tabular}

The comparative study of postoperative RBS of 40 patients in either group showed that RBS values were generally higher in the dexamethasone group than in the control group in the first 18 hours postoperatively. The difference in the RBS values between the 2 groups was higher 6 hours postoperatively than in the 12-hour and 18-hour values. However, when the 24 -hour postoperative values were taken the control group showed a higher mean RBS value than in the dexamethasone group, but the difference was not significant. Majority of patients enrolled in the study in both the groups did not complain of any postoperative gastric irritation. 6 hours postoperatively, 8 patients in the dexamethasone group had gastric irritation while the number was 5 in the control group. One patient from each group complained of gastric irritation 12 hours after surgery. Meanwhile only 1 patient from the dexamethasone group complained of gastric irritation 18 hours after surgery. Nobody in either group had gastric irritation 24 hours after surgery.

\section{DISCUSSION}

Patients belonging to ASA class I were included in the study. Patients between the age group of 30 and 50 years were included in the study. Mean age of group C (Control group) was $39.9 \pm 6.7$ years and that of group D (dexamethasone group) was $41.6 \pm 5.7$ years. Majority of patients were females in both the groups $(72 \%$ in the control group and $52 \%$ in the dexamethasone group).

Park et $\mathrm{al}^{16}$ in their prospective, randomised, doubleblinded, controlled study divided patients into 3 groups with the first 2 groups receiving prophylactic dexamethasone injection and the $3^{\text {rd }}$ group receiving placebo. Results showed that the incidence and severity of POST was significantly lower in the groups one and two who were treated with dexamethasone (incidence of POST in group one: $31 \%$, group two: $11 \%$, group three: $53 \%$ ). The $0.2 \mathrm{mg} / \mathrm{kg}$ dose was effective for the reduction of incidence and severity of POST and hoarseness at both 1 and 24 hours after extubation while the $0.1 \mathrm{mg} / \mathrm{kg}$ dose only produced statistically significant reduction of symptoms at 1 hour. Researchers ultimately determined that the prophylactic use of intravenous dexamethasone significantly decreased the incidence and severity of POST and hoarseness. Siji Thomas and Suhara Beevi15 in their study on postoperative sore throat after endotracheal intubation concluded that preoperative administration of dexamethasone $8 \mathrm{mg}$ IV reduces the incidence and severity of postoperative sore throat in patients receiving general anaesthesia with endotracheal intubation. Bagchi D and colleagues ${ }^{17}$ in their study found out that at 1 hour post-extubation, the incidence of sore throat in the control group was $48.9 \%$ compared with $18.8 \%$ in the dexamethasone group $(\mathrm{P}<0.002)$. They concluded that prophylactic intravenous dexamethasone in a dose of 0.2 $\mathrm{mg} / \mathrm{kg}$ can reduce the incidence of postoperative sore throat at 1 hour post-extubation by around $30 \%$, with the efficacy being around $60 \%$. In my study, a good number of patients in either group had throat irritation in the first 30 minutes after surgery but after that incidence of sore throat decreased in both the groups. Postoperative sore throat was significantly reduced in the dexamethasone group compared to the control group especially in the initial few postoperative hours. Clore JN, Thurby-Hay $\mathrm{L}^{18}$ in their study reported that glucocorticoid-induced hyperglycaemia is common in patients with and without diabetes. The odds ratio for newonset diabetes mellitus in patients treated with glucocorticoids ranges from approximately 1.5 to 2.5 . Total glucocorticoid dose and duration of therapy are strong predictors of diabetes induction. Two independent studies 
conducted by Piper JM et $\mathrm{al}^{19}$ and Conn HO, Poynard $\mathrm{T}^{20}$ concluded that peptic ulcer is a rare complication of corticosteroid therapy that should not be considered a contraindication when steroid is used. However, the combination of glucocorticoids and NSAIDs results in a synergistic increase in the incidence of GI events. In my study, there was not much difference between the 2 groups as far as gastric irritation is concerned after intravenous dexamethasone administration. Out of 80 patients studied, only 13 patients ( 8 in the study group and 5 in the control group) complained of gastric irritation 6 hours after surgery.

\section{CONCLUSION}

The dexamethasone group showed comparatively lesser incidence of sore throat than the control group especially in the first hour after surgery. Thereafter the complaints of sore throat decreased in both the groups, the dexamethasone group having fewer number of patients with sore throat than the control group. Notably nobody from either group had severe sore throat following surgery, with a small percentage of patients belonging to both groups having moderate sore throat. Regarding RBS values following dexamethasone intravenous administration, the study clearly shows elevated RBS levels in the dexamethasone group especially in the initial 18 hours after surgery. There was not much difference between the 2 groups as far as gastric irritation is concerned after intravenous dexamethasone administration. Thus, based on the study, dexamethasone has some advantage in reducing postoperative sore throat in patients undergoing endotracheal intubation. There was no significant gastric irritation in patients receiving dexamethasone, but their RBS was elevated compared to the study group especially in the early postoperative hours.

\section{REFERENCES}

[1] Aitkenhead AR, Smith G. The practical conduct of anaesthesia. In: Textbook of Anaesthesia. $3^{\text {rd }}$ edn. London, England: Churchill Livingstone, 1996:319-33.

[2] Biro P, Seifert B, Pasch T. Complaints of sore throat after tracheal intubation: prospective evaluation. Eur J Anaesthesiol 2005;22(4):307-11.

[3] Chen KT, Tzeng JI, Lu CL, et al. Risk factors associated with postoperative sore throat after tracheal intubation: an evaluation in the postanesthetic recovery room. Acta Anaesthesiol Taiwan 2004;42(1):3-8.

[4] Mencke T, Echternach $\mathrm{M}$, Kleinschmidt S, et al. Laryngeal morbidity and quality of tracheal intubation: a randomized controlled trial. Anesthesiology 2003;98(5):1049-56.

[5] Jaensson M, Olowsson LL, Nilsson U. Endotracheal tube size and sore throat following surgery: a randomizedcontrolled study. Acta Anaesthesiol Scand 2010;54(2):147-53.
[6] Keipert JA, Kelly R. Temporary Cushing's syndrome from percutaneous absorption of betamethasone 17valerate. Med J Aust 1971;1(10):542-4.

[7] Ng PC, Fok TF, Wong GW, et al. Pituitary-adrenal suppression in preterm, very low birth weight infants after inhaled fluticasone propionate treatment. J Clin Endocrinol Metab 1998;83(7):2390-3.

[8] Fisher DA. Adverse effects of topical corticosteroid use. West J Med 1995;162(2):123-6.

[9] McKenzie AW, Stoughton RB. Percutaneous absorption of steroids. Arch Dermatol 1962;86(5):611-4.

[10] Livanou T, Ferriman D, James VH. Recovery of hypothalamo-pituitary-adrenal function after corticosteroid therapy. Lancet 1967;2(7521):856-9.

[11] Thomas DV. Hoarseness and sore throat after tracheal intubation. Small tubes prevent. Anesthesia 1993;48(4):355-6.

[12] Fuller PB. The relationship between pre-intubation lidocaine and post-anesthesia sore throat. AANA J 1992;60(4):374-8.

[13] McHardy FE, Chung F. Postoperative sore throat: cause, prevention and treatment. Anaesthesia 1999;54(5):444-53.

[14] Oczenski W, Krenn H, Dahaba AA, et al. Complications following the use of the Combitube, tracheal tube and laryngeal mask airway. Anesthesia 1999;54(12):11615.

[15] Thomas S, Beevi S. Dexamethasone reduces the severity of postoperative sore throat. Can J Anaesth 2007;54(11):897-901.

[16] Park SH, Han SH, Do SH, et al. Prophylactic dexamethasone decreases the incidence of sore throat and hoarseness after tracheal extubation with a double lumen endobronchial tube. Anesth Analg 2008;107(6):1814-8.

[17] Bagchi D, Mandal MC, Das S, et al. Efficacy of intravenous dexamethasone to reduce incidence of postoperative sore throat: a prospective randomized controlled trial. J Anaesthesiol Clin Pharmacol 2012;28(4):477-80.

[18] Clore JN, Thurby-Hay L. Glucocorticoid-induced hyperglycemia. Endocr Pract 2009;15(5):469-74.

[19] Conn HO, Poynard T. Corticosteroids and peptic ulcer: meta-analysis of adverse events during steroid therapy. J Intern Med 1994;236(6):619-32.

[20] Piper JM, Ray WA, Daugherty JR, et al. Corticosteroid use and peptic ulcer disease: role of nonsteroidal antiinflammatory drugs. Ann Intern Med 1991;114(9):735-40. 